\title{
Hypoxic Preconditioning Eliminates Differences in the Innate Resistance of Rats to Severe Hypoxia
}

\author{
Elena I. Zakharova*, Alexander M. Dudchenko \\ Laboratory of General Pathology of Cardiorespiratory Systems, Institute of General Pathology and Pathophysiology, Moscow, Russia \\ Email: `zakharova-ei@yandex.ru,amdudchenko@gmail.com
}

How to cite this paper: Zakharova, E.I. and Dudchenko, A.M. (2016) Hypoxic Preconditioning Eliminates Differences in the Innate Resistance of Rats to Severe Hypoxia. J. Biomedical Science and Engineering, 9, 563575.

http://dx.doi.org/10.4236/jbise.2016.912049

Received: October 27, 2016

Accepted: November 19, 2016

Published: November 22, 2016

Copyright $\odot 2016$ by authors and Scientific Research Publishing Inc. This work is licensed under the Creative Commons Attribution International License (CC BY 4.0).

http://creativecommons.org/licenses/by/4.0/

(c) (i) Open Access

\begin{abstract}
Hypoxic preconditioning is able to increase the body's resistance to hypoxic/ischemic stress. Understanding how to apply the hypoxic response to initiate the protective mechanism of ischemic preconditioning is a high priority. However, the relationship between innate resistance to hypoxic stress and preconditioning efficiency of moderate hypoxia has been poorly studied. In our work, the efficiency of single moderate hypobaric hypoxia $(\mathrm{HBH})$ for resistance to severe hypobaric hypoxia $(\mathrm{SHBH})$ was studied on intact rats and those pre-tested under SHBH with low, intermediate and high resistance to hypoxia. HBH has a significant preconditioning action on the resistance to hypoxia over a wide range from 270 to $1464 \mathrm{~s}$ ( 4.5 to $24.5 \mathrm{~min}$ ) and at the same time eliminates the differences in the endurance under $\mathrm{SHBH}$ between all rat groups. It is concluded that 1) HBH preconditioning efficiency does not depend on an innate resistance to $\mathrm{SHBH}$ and prior hypoxic experience of rats; and 2) the pretesting to severe hypoxia has no value for predicting the hypoxic preconditioning efficiency and study of adaptive mechanisms.
\end{abstract}

\section{Keywords}

Resistance to Hypoxic Stress, Severe Hypoxia, Hypoxic Preconditioning

\section{Introduction}

Short episodes of non-damaging stress impacts of different aetiologies are capable of increasing the body's resistance to various pathological factors. Among them, the hypoxic/ischemic adaptive factors are of greatest interest, because it is likely that the hypoxic component (tissue hypoxia) forms the pathogenesis of many diseases. Murry et al. [1] were the first to describe the protective effect of the short ischemic exposure against ischemic stroke, suggested a preconditioning term for this phenomenon. Subsequently, the authors made it clear that the second most important component of the 
adaptive effect is the subsequent re-oxygenation (reperfusion) [2].

The hypoxic and ischemic preconditionings are two closely related processes by nature and therapeutic potential. Hypoxic factor is the main in ischemic preconditioning effect. Hypoxic or ischaemic preconditioning in vitro and in vivo is a powerful protective mechanism against ischaemic injury and other acute injuries in many organ systems. Thus, the preconditioning effects were identified for the heart [1] [3] [4] [5], brain [6]-[13], liver [14] [15] [16] and kidneys [17] [18] in vivo.

Hypoxic/ischaemic preconditioning is a multifactorial process requiring the interaction of numerous signals, second messengers and effector mechanisms [8] [9] [12] [13] [19] [20] [21]. Understanding how to apply the hypoxic response to initiate the protective mechanism of ischemic preconditioning is a high priority [13]. Direct preconditioning action or the molecular effectors of the hypoxic protective response could reveal promising therapeutic targets.

Systemic hypoxic preconditioning is achieved by short-term adaptation to a single one-three-hour moderate hypoxic continuous or intermittent exposure, in which hypoxia alternates with normoxia or hyperoxia [11] [12] [21] [22] and may be maintained for one day [11] [20] [22] [23]. The advantage of the short-term adaptation, especially after continuous hypobaric hypoxia, is the most pronounced and rapid preconditioning effect in the first minutes of the re-oxygenation [20] [22] [23].

Animals of any species show very different resistances to hypoxia. This implies different mechanisms of resistance. Therefore, pre-testing has been developed for the study of mechanisms of severe hypoxia, which are incompatible with life $\left(3 \%-4.5 \% \mathrm{O}_{2}\right.$ for rats). The idea belongs to Purushottam and Ghosh [24]. Experimental animals were pre-tested under the same severe hypoxic conditions and divided into groups of high, intermediate and low resistance to hypoxia [24] [25] [26] [27] [28]. Later, the pretesting under severe hypoxia was applied to rats for the investigation of mechanisms of hypoxic preconditioning [22] [23].

Using this pre-test, we found that a single session of moderate hypobaric hypoxia $\left(\mathrm{HBH}, 11 \% \mathrm{O}_{2}, 60 \mathrm{~min}\right.$ ) eliminated differences in the resistance to severe hypobaric hypoxia ( $\mathrm{SHBH}, 4.5 \% \mathrm{O}_{2}$ ) between the high- and low-resistant rats [29]. However, it was unclear whether this is a consequence of $\mathrm{SHBH}$ pre-testing or $\mathrm{HBH}$ action only.

Since the resolution of this issue was directly related to the mechanisms of hypoxic preconditioning, a comparative study of the high-, intermediate- and low-resistant rats pre-tested under $\mathrm{SHBH}$, and of the intact rats was carried out. In these rat groups, the $\mathrm{HBH}$ influence was evaluated in the resistance to SHBH.

\section{Materials and Methods}

\subsection{Animals and Ethical Policy}

Experiments were performed on laboratorial male outbred albino rats aged $2-2.5$ months (weight $200-250 \mathrm{~g}$ ) at the beginning of the study. The rats were supplied from the animal nursery "Light Mountains" (Russian Federation) and then kept in the vivarium of the Institute of General Pathology and Pathophysiology. 
All animal care and experimental procedures were conducted in accordance with the official regulations of the European Communities Council Directive on the use of laboratory animals of 24 November 1986 (86/609/EEC). The study was approved by the Ethical Committee of the Institute of General Pathology and Pathophysiology created by the Institute Order "On the formation of the new Ethical Committee" number 01-01/147 of 12 October 2009. All efforts were made to minimize the number of animals used and their suffering.

The rats were housed in a temperature-controlled room $\left(20^{\circ} \mathrm{C}-24^{\circ} \mathrm{C}\right)$ with $5-7$ animals per cage, with free access to food and water, and maintained with a $12 \mathrm{~h}$ light/ dark cycle. The rats were handled for at least two consecutive days prior to being placed in the pressure chamber. At the end of the experiment, the animals were killed by inhalation of $\mathrm{CO}_{2}$ euthanasia using apparatus for euthanasia AE0904 (Open Science, Russian Federation).

\subsection{Hypoxic Models}

We used the same hypoxic models as before [22] [29] [30]. Hypoxia of varying severity was created in the pressure chamber. The barometer of the chamber (altitude gauge) was calibrated to an altitude above sea level. The rats in the chamber "were raised" at a speed of $50 \mathrm{~m} / \mathrm{s}$ to the adaptive altitude of $5000 \mathrm{~m}\left(\mathrm{HBH}, 3.0 \mathrm{~Pa}\right.$, equivalent to $11 \% \mathrm{O}_{2}$, $60 \mathrm{~min}$ ) or to the critical altitude of $11500 \mathrm{~m}\left(\mathrm{SHBH}, 1.2 \mathrm{~Pa}\right.$, equivalent to $\left.4.5 \% \mathrm{O}_{2}\right)$. In the latter test, resistance to hypoxia was recorded with respect to endurance under SHBH conditions that was time $(\mathrm{T})$ until agonal inspiration (apnea) in combination with a loss of voluntary control of body tone.

\subsection{Experimental Protocol}

Some of the rats were pre-tested under SHBH conditions and the values of innate primary T (T1) were estimated. The animals were divided into groups of low, intermediate and high resistance to hypoxia with $\mathrm{T} 1<210 \mathrm{~s}$, T1 between $210-420 \mathrm{~s}$ and $\mathrm{T} 1>420 \mathrm{~s}$, respectively. For the following 4 - 5 weeks, all rats were kept under standard vivarium conditions, after which the low-, intermediate-, high-resistant and not pre-tested intact rats were subdivided into the experimental and control groups.

The rats of experimental HBH groups were subjected to a single $\mathrm{HBH}$ session; four min after the end of the session, the rats from each $\mathrm{HBH}$ group were subjected to SHBH. Values of T1 for the intact rats and T2 for the high-, intermediate- and low-resistant rats were estimated.

Each experimental group had a control group. The control groups duplicated the experimental groups, but the $\mathrm{HBH}$ exposure was omitted from the protocol. All of the experiments with the influence of $\mathrm{HBH}$ were tested simultaneously to the corresponding control group. Thus, all rats from the pre-tested control and experimental (HBH) groups were subjected to $\mathrm{SHBH}$ exposure twice: the first time, when rats pre-tested (T1) and then during the experiment (T2) after $\mathrm{HBH}$ (the $\mathrm{HBH}$ groups) or without it (the control groups). Unlike the pre-tested rats, those intact of the control and $\mathrm{HBH}$ 
groups were subjected to SHBH exposure only once during the experiment, and, accordingly, had values of $\mathrm{T} 1$.

All data ( $\mathrm{T} 1$ and $\mathrm{T} 2$ ) were generated in a double blind manner which has been achieved thanks to the technical assistance of our colleague.

\subsection{Statistics}

The data were calculated using the non-parametric one-sided Fisher's Exact Test and the r-criterion of the Pearson's correlative test in Microsoft Excel with the formula being adjusted for a small number of observations $(\mathrm{n}=4$ - 15) [31]. Differences were considered to be statistically significant if $P<0.05$. Data are shown as means and standard errors (SE) in Figures 1-3 and as individual values in Figure 2, Figure 4, and Figure 5. The quantity of rats in each group is given in the figure legends.

\section{Results and Discussion}

\subsection{Resistance to SHBH of the Intact, High and Low Resistance Rats in the Control Groups}

Mean values of the resistance to hypoxia in the control pre-tested rat groups are shown in Figure 1. In our study, the rats with low, intermediate and high resistance to $\mathrm{SHBH}$ comprised $36 \%, 27 \%$ and $38 \%$, respectively, of the tote pre-tested rats $(n=64)$, which corresponds to the usual composition of outbred rats in an experimental lot [28] [32].

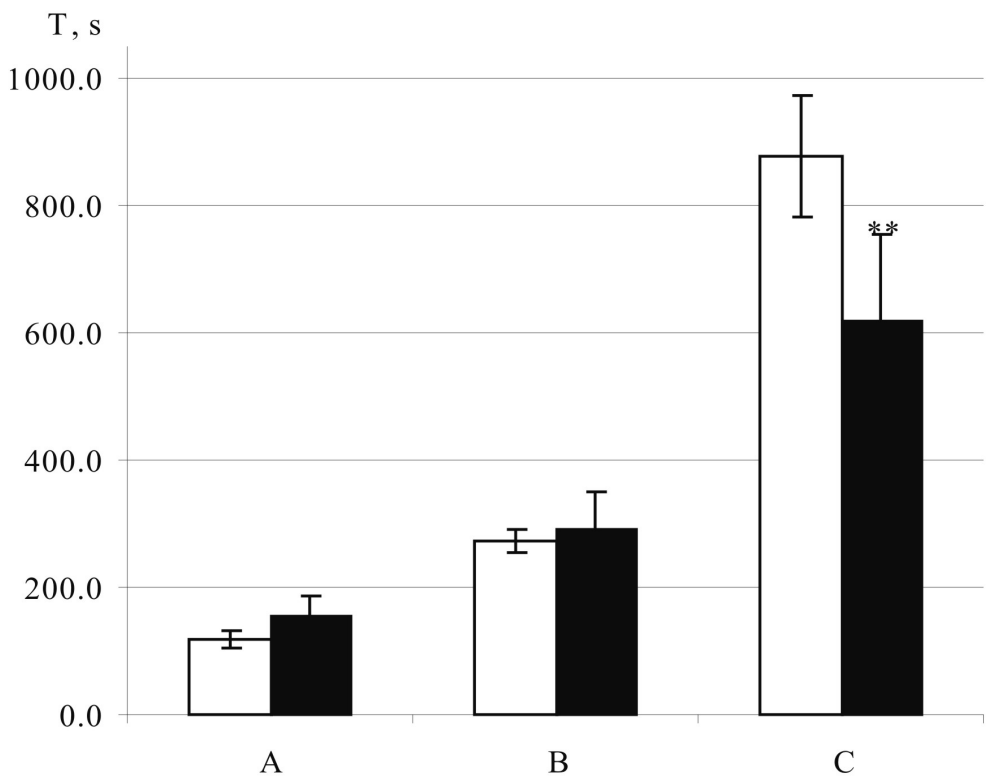

Figure 1. Resistance to $\mathrm{SHBH}$ in the control groups of low- (A), intermediate(B) and high-resistant (C) rats. T(s), endurance under SHBH exposure. T values are means \pm SE. For each group of bars: empty bars, T1 values of the resistance to SHBH under primary hypoxic exposure; black bars, T2 values of the resistance to $\mathrm{SHBH}$ under secondary hypoxic exposure. $\mathrm{N}=12,9$, and 14 for $\mathrm{A}, \mathrm{B}$, and $\mathrm{C}$, respectively. ${ }^{*} P<0.025$ between $\mathrm{T} 2$ and $\mathrm{T} 1$ within the highresistant rat group $(\mathrm{C})$, the Fisher's Exact test. 


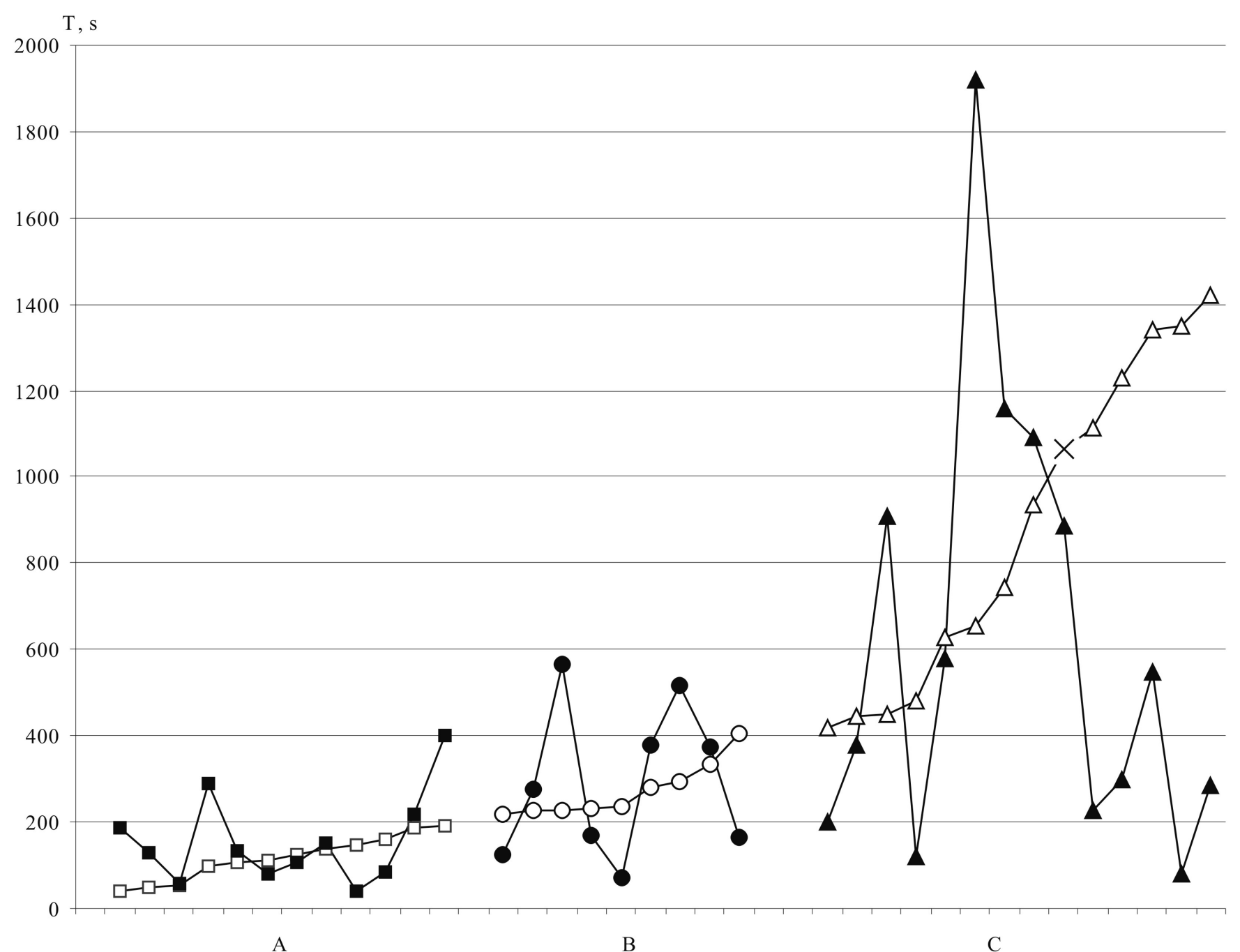

Figure 2. Individual values of the resistance to SHBH in the control groups of low- (A), intermediate- (B) and high-resistant (C) rats. Empty squares, circles or triangles, individual T1 values for A, B and C, respectively; black squares, circles or triangles, the corresponding individual T2 values. Cross mark in T1 sequences of the high-resistant rat group (C), the value of T1, from which all T2 < T1. In T1 sequences, individual values are located according to an increase. In T2 sequences, each $\mathrm{T} 2$ value corresponds to the T1 value to demonstrate uncertainty of T2 values. $R=+0.323,+0.054$, and -0.342 for T1-T2 in A, B, and C, respectively, $\mathrm{n}=12,9$, and 14 as in Figure $1, P>$ 0.05 , the Pearson's correlative test.

The control group of intact rats also included all categories of the rat resistance (38\%, $13 \%$ and $50 \%$ for low-, intermediate- and high-resistant rats, respectively, $\mathrm{n}=8$ ).

With repeated testing, the mean values of $\mathrm{T} 2$ confirmed the $\mathrm{T} 1$ values in the groups of low- and intermediate-resistant rats (Figure 1(a) and Figure 1(b)). In the highresistant rat group, half of the rats showed T2 $<420 \mathrm{~s}$. In this rat group, the mean T2 value was significantly lower than $\mathrm{T} 1$ (Figure $1(\mathrm{c})$ ) and the values were $\mathrm{T} 2<\mathrm{T} 1$ for all rats with $\mathrm{T} 1>930-1050 \mathrm{~s}$ (Figure 2(c)). In our previous study of $\mathrm{HBH}$ effects, the mean $\mathrm{T} 2$ value of high-resistant rats was not significantly reduced compared with $\mathrm{T} 1$ value [29]. At the same time, a significant decrease of T2 values in rats with T1 $>900$ $1020 \mathrm{~s}$ are confirmed in other studies (unpublished). The same decrease of T2 values 


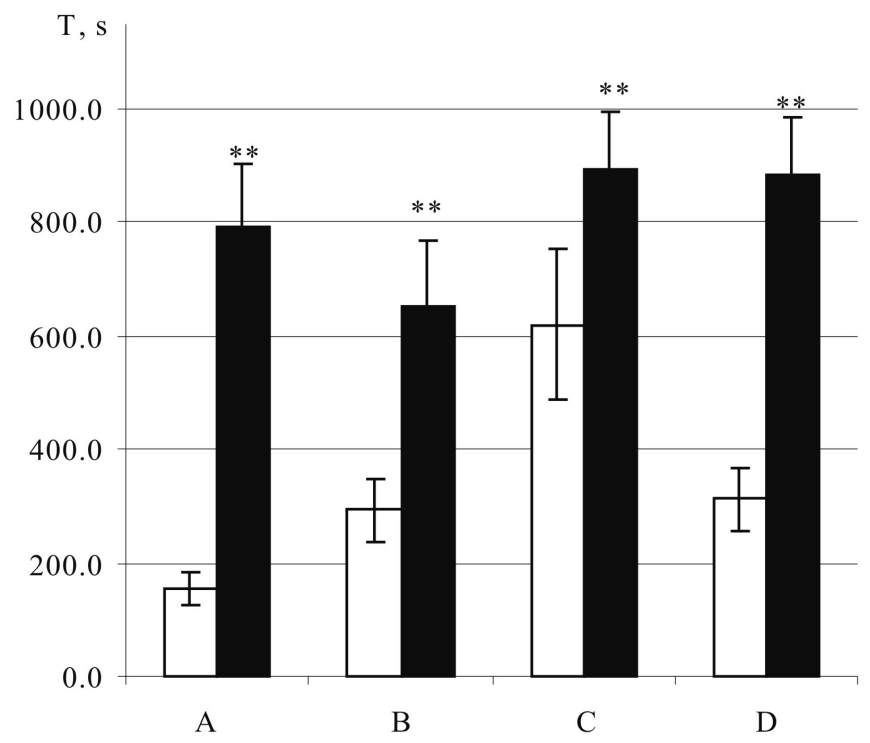

Figure 3. HBH effects on the resistance to SHBH of the low- (A), intermediate- (B), high-resistant (C) and intact (D) rats. $\mathrm{T}$ values are expressed as means \pm SE. For each group of bars: empty bars, $\mathrm{T} 2$ values in the control pre-tested rat groups (A, B, C, SHBH only; $\mathrm{n}=12,9,14$, respectively) and $\mathrm{T} 1$ value in the control intact rat group (D, SHBH only, $\mathrm{n}=8$ ); black bars, T2 $(\mathrm{A}, \mathrm{B}, \mathrm{C})$ or T1 values (D) in the corresponding $\mathrm{HBH}$ groups $(\mathrm{HBH}+\mathrm{SHBH} ; \mathrm{n}=11,8,10$ and 9 in $\mathrm{A}, \mathrm{B}, \mathrm{C}$ and $\mathrm{D}$, respectively). ${ }^{\star *} P<0.025$ compared to the respective control, the Fisher's Exact test.

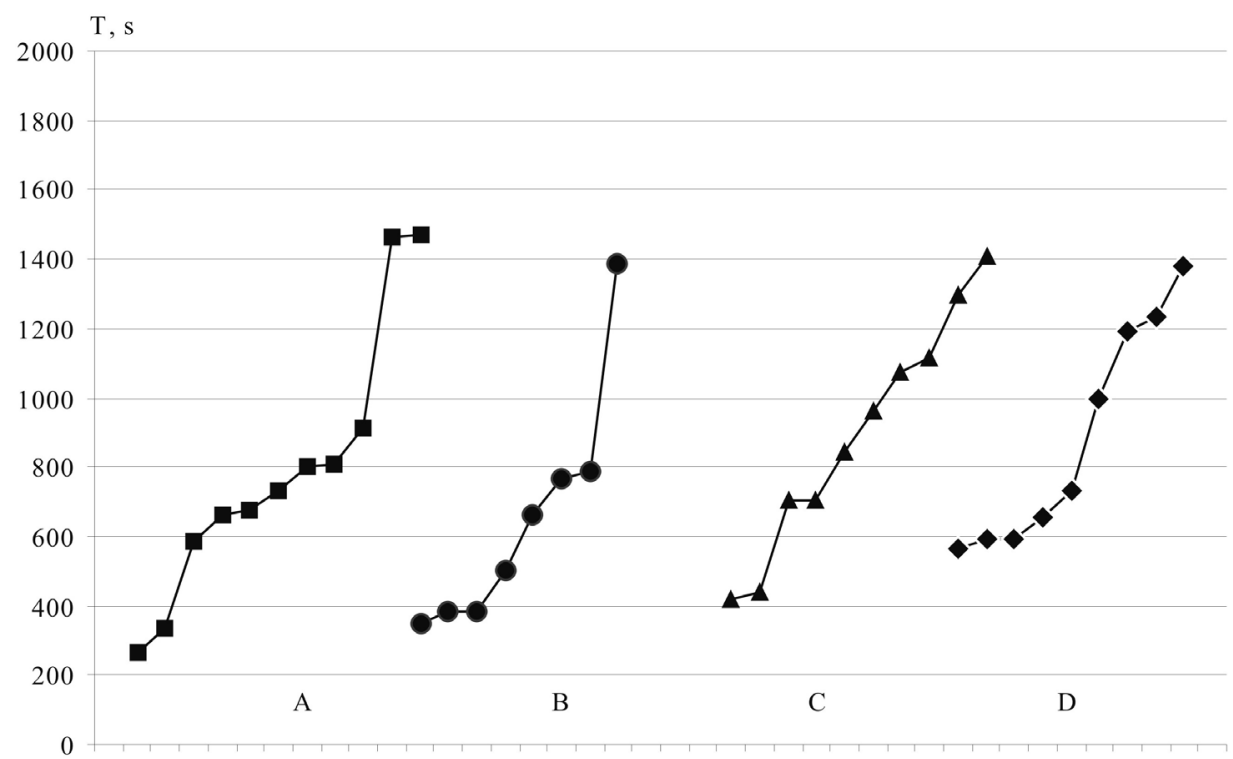

Figure 4. Individual values of the resistance to $\mathrm{SHBH}$ after $\mathrm{HBH}$ in the low- (A), intermediate(B), high-resistant (C) and intact (D) rat groups. For each rat group, marks indicate the individual values of resistance to $\mathrm{SHBH}$ after $\mathrm{HBH}$ to demonstrate that $\mathrm{T}$ values of all $\mathrm{HBH}$ groups formed the same variational series. $\mathrm{N}=11,8,10$, and 9 in $\mathrm{A}, \mathrm{B}, \mathrm{C}$, and $\mathrm{D}$ as in the corresponding $\mathrm{HBH}$ groups in Figure 3. 


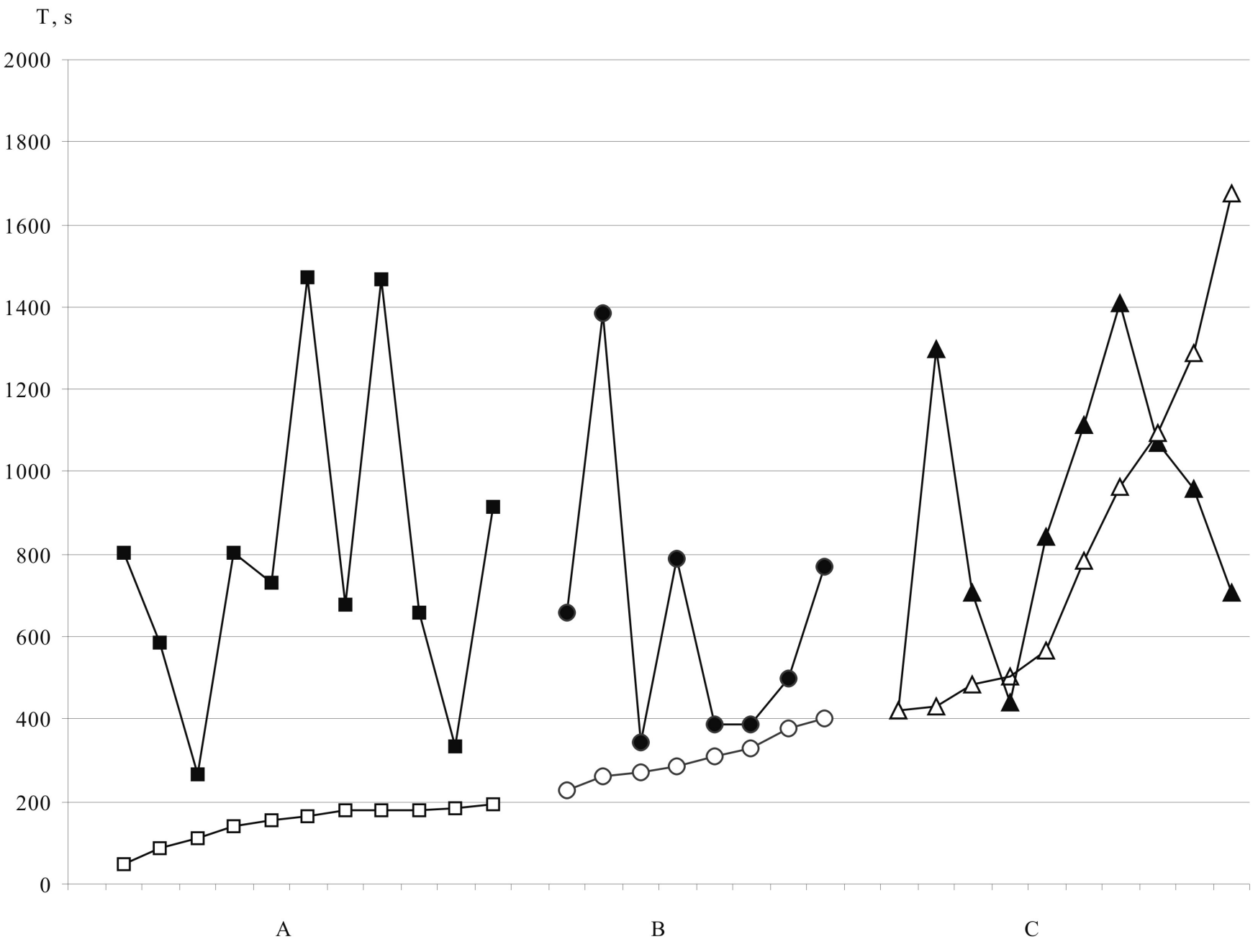

Figure 5. Individual values of the resistance to $\mathrm{SHBH}$ in the $\mathrm{HBH}$ groups of low- (A), intermediate- (B) and high-resistant (C) rats. Empty squares, circles or triangles, individual T1 values for A, B and C, respectively; black squares, circles or triangles, the corresponding individual T2 values after $\mathrm{HBH}$ exposure. T values are disposed as in Figure 2: T1 values are located according to increase; each T2 value corresponds to the $\mathrm{T} 1$ value to demonstrate absolute absence of T2 dependence on T1. $R=+0.244,-0.218$ and +0.182 for $\mathrm{T} 1-\mathrm{T} 2$ in $\mathrm{A}$, $\mathrm{B}$, and C, respectively, $\mathrm{n}=12,9$, and 14 as in Figure 3 and Figure 4, $P>0.05$, the Pearson's correlative test.

was observed 30 - 40 min after pre-testing under more severe hypoxia $\left(0.8 \mathrm{~Pa}, 3 \% \mathrm{O}_{2}\right)$ in Nembutal-anesthetized rats with T1 > $900 \mathrm{~s}$ [28]. Thereby, the data of this study reflect typical relations between $\mathrm{T} 1$ and $\mathrm{T} 2$ in the high-resistant rat group.

As a rule, rats with $\mathrm{T} 1<930 \mathrm{~s}$ had significant multidirectional deviations of $\mathrm{T} 2$ from T1 values (Figure 2).

Vector of the deviations showed virtually equal probability in any group of rats. As a result, significant T2 dependence on T1 was absent in all control pre-tested rat groups. Moreover, a sufficiently high probability to repeat their own category of resistance under the secondary SHBH exposure took place only among the low-resistant rats, while such probability was absent among intermediate- and high-resistant rats. Thus, there was a high level of uncertainty as to the last two groups, regarding in what category the $\mathrm{HBH}$ effects were studied. 
Therefore, we assumed that the single pre-test under $\mathrm{SHBH}$ reserves a prolonged adaptive trace. Earlier, on the models of chronic brain hypoperfusion (2VO model), we had found a protective effect of pre-testing for high- and low-resistant rats (see below). According to the modern physiological concepts, the brain can generate long-term memory [33], and in a broader sense, any organ can form "biological memory" [34] in response to a single adequate extreme stimulus.

\subsection{HBH Effects on the Resistance to SHBH of the Intact, High and Low Resistance Rats}

$\mathrm{HBH}$ markedly increased the mean values of the resistance of rats to SHBH in all investigated groups (Figure 3). After $\mathrm{HBH}$, the individual $\mathrm{T}$ values in the low- and intermediate-resistant rats and in the intact rats had no overlap with values for the control groups. In the high-resistant rats, $\mathrm{HBH}$ actually restored the original status of the group. The mean $\mathrm{T} 2$ value in the $\mathrm{HBH}$ high-resistant rat group was significantly higher than $\mathrm{T} 2$ value in the control group and did not differ from own mean $\mathrm{T} 1$ value $(\mathrm{T} 2=$ $896 \mathrm{~s} \pm 101 \mathrm{~s}$ versus $\mathrm{T} 1=821 \mathrm{~s} \pm 128 \mathrm{~s}$ ).

Accordingly, $\mathrm{HBH}$ has a marked preconditioning effect on rats, increasing or restoring (in the case of the high-resistant rats) resistance to SHBH. This is consistent with the data for the low-resistant rats [22] [23] and confirms our previous data for the lowand high-resistant rats [29].

After $\mathrm{HBH}$ sessions, all rat groups showed a similar range of values for resistance to SHBH with mean T values of $792 s \pm 108 \mathrm{~s}, 654 \mathrm{~s} \pm 114,896 \mathrm{~s} \pm 101$ and $882 \mathrm{~s} \pm 102 \mathrm{~s}$ in the low-, intermediate-, high-resistant and intact rat groups, respectively (Figure 3 ). In fact, the $\mathrm{T}$ values of these groups formed the same variational series (Figure 4). Accordingly, individual values initiated by $\mathrm{HBH}$ were completely random in nature with respect to their own $\mathrm{T} 1$ values in any pre-tested rat group (Figure 5).

These results also confirm our previous data for high- and low-resistant rats [29]. The same $\mathrm{HBH}$ effect for the intact- and intermediate-resistant rat groups was revealed for the first time, and was unexpected for us with regard to the intact rats. As revealed earlier, mortality was 3 - 5.5 times lower among both the high- and low-resistance rats compared with the intact animals under 2VO conditions (unpublished). Analysis of the results of this study also points to a trace which remains after the pre-testing under SHBH conditions and affects the resistance to hypoxia. Therefore, we assumed that $\mathrm{HBH}$ affects the resistance of the intact rats with another compared with those of the pre-tested rats.

The same preconditioning effects of $\mathrm{HBH}$ in the intact rats and those pre-tested under SHBH can be explained only by the fact that $\mathrm{HBH}$ preconditioning is, apparently, realized by its own mechanisms which do not depend on innate resistance to $\mathrm{SHBH}$ and prior hypoxic experiences.

Thus, a single severe hypoxia alters the resistance to secondary severe hypoxia and does not affect the preconditioning efficiency. Furthermore, the pre-testing under $\mathrm{SHBH}$ alters preconditioning synaptic mechanisms. In the intact rats, the opposite cholinergic reaction to $\mathrm{HBH}$ was revealed in the synaptic pool in the brain stem and cortex 
those in the high and low resistant rats [30]. This implies that the preliminary estimate of resistance to severe hypoxia has no value for predicting the hypoxic preconditioning efficiency for pre-tested rats.

Therefore, we would like to emphasize a problem that awaits solution. Individual sensitivity to adaptive hypoxia and risk of no dangerous side effects (sickness, dizziness, tendency to hyperventilation, some others) are well known in clinical practice. Therefore, be sure to monitoring of physiological parameters of a patient is carried out at the beginning of hypoxic training to correct training regime [35] [36]. In our study, we used a very soft hypoxic model. Monitoring of physiological parameters did not reveal individual sensitivity and shows no side effects in rats under HBH conditions [37] [38]. Nevertheless, the limit of resistance to hypoxia which was initiated by $\mathrm{HBH}$ varies over a wide range. The extreme values of resistance to hypoxia after $\mathrm{HBH}$ could differ significantly, and by up to 5.5 times in our experiments. It is very likely that the reaction to $\mathrm{HBH}$ can be based on different mechanisms of hypoxic preconditioning. This is also indicated by the inhibitory effects of methyllycaconitine (MLA, a selective antagonist of the alpha 7 subtype of nicotinic receptors) in the group of low-resistant rats, which took place only in the range of rats with high efficiency of $\mathrm{HBH}$ [29].

Thus, for the hypoxic preconditioning efficiency predicting and study of innate adaptive mechanisms, it is necessary to look for other, non-stressor methods for the separation of animals in their sensitivity to adaptive hypoxia. This will help to better understand the mechanisms of hypoxic preconditioning and to identify additional novel therapeutic targets for diverse acute and, possibly, chronic pathologies [13] [39].

Standardization of the range of adaptive resistance to stress was observed in experiments with stressors of other types. August and Wistar are lines of rats with different genetic resistance to acute emotional stress [37]. Classical criterion of the resistance to emotional stress is gastric ulceration (number of ulcers and size of affected area). Both indicators were usually 7 - 10.5 times higher in Wistar rats than in August rats [40] [41] [42]. Preliminary intermittent action of the moderate stressor of the same etiology led to a decrease in the ulceration in Wistar rats (3 - 6 times) and, conversely, to an increase (to 1.2 - 2 times) of this in August rats in response to strong emotional stress [41] [42]. At the same time, illustrations in both articles demonstrate that the stress indicators in Wistar and August rats become equal after emotional stress adaptation.

Interestingly, the resistance to emotional stress increased both in Wistar and August rats and, thereby, preserved significant differences in the values of stress indicators after the hypoxic adaptation [40]. Thus, it is possible that the phenomenon of the standardization of the resistance to stressors occurs only after adaptation to factors of the same etiology.

We assume that $\mathrm{HBH}$ initiates the optimum homeostatic resistance to $\mathrm{SHBH}$ of rat as a species. It is possible that such resistance reflects the most balanced nervous organization of physiological functions in the given environmental conditions.

\section{Conclusions}

1) $\mathrm{HBH}$ has a marked hypoxic preconditioning effect on rats, increasing and restor- 
ing the resistance to $\mathrm{SHBH}$.

2) The preliminary estimate of resistance to severe hypoxia has no value for predicting the hypoxic preconditioning efficiency for pre-tested rats and the study of preconditioning mechanisms.

3) $\mathrm{HBH}$ preconditioning is realized by its own mechanisms which eliminate the differences in resistance to hypoxia between groups of rats with different innate resistance to severe hypoxia and with different prior hypoxic experiences.

\section{Acknowledgements}

We are grateful to the direction of Institute of General Pathology and Pathophysiology that supported and funded our research. And we would like to thank the team of the Proof-Reading-Service.com and personally Louise Bourdon for proofreading the English of our manuscript. Also we would like to thank of our colleague R. A. Kopaladze for technical assistance.

\section{References}

[1] Murry, C.E., Jennings, R.B. and Reimer, K.A. (1986) Preconditioning with Ischemia: A Delay of Lethal Cell Injury in Ischemic Myocardium. Circulation, 74, 1124-1136. https://doi.org/10.1161/01.CIR.74.5.1124

[2] Richard, V., Murry, C.E. and Reimer, K.A. (1995) Healing of Myocardial Infarcts in Dogs. Effects of Late Reperfusion. Circulation, 92, 1891-1901.

https://doi.org/10.1161/01.CIR.92.7.1891

[3] Tajima, M., Katayose, D., Bessho, M. and Isoyama, S. (1994) Acute Ischaemic Preconditioning and Chronic Hypoxia Independently Increase Myocardial Tolerance to Ischaemia. Cardiovascular Research, 28, 312-319. https://doi.org/10.1093/cvr/28.3.312

[4] Duan, Z., Zhang, L., Liu, J., Xiang, X. and Lin, H. (2012) Early Protective Effect of Total Hypoxic Preconditioning on Rats against Systemic Injury from Hemorrhagic Shock and Resuscitation. Journal of Surgical Research, 178, 842-850. https://doi.org/10.1016/j.jss.2012.04.069

[5] Xu, R., Sun, Y., Chen, Z., Yao, Y. and Ma, G. (2016) Hypoxic Preconditioning Inhibits Hypoxia-Induced Apoptosis of Cardiac Progenitor Cells via the PI3K/Akt-DNMT1-p53 Pathway. Scientific Reports, 6, 30922. https://doi.org/10.1038/srep30922

[6] Kitagawa, K., Matsumoto, M., Tagaya, M., Hata, R., Ueda, H., Niinobe, M., Handa, N., Fukunaga, R., Kimura, K., Mikoshiba, K. and Kamada, T. (1990) "Ischemic Tolerance" Phenomenon Found in the Brain. Brain Research, 528, 21-24. https://doi.org/10.1016/0006-8993(90)90189-I

[7] Gidday, J.M., Fitzgibbons, J.C., Shah, A.R. and Park, T.S. (1994) Neuroprotection from Ischemic Brain Injury by Hypoxic Preconditioning in the Neonatal Rat. Neuroscience Letters, 168, 221-224. https://doi.org/10.1016/0304-3940(94)90455-3

[8] Samoilov, M.O. (1999) Brain and Adaptation. Molecular-Cellular Mechanisms. Turusel, St. Petersburg. (In Russian)

[9] Stone, T.W. (2003) Pre-Conditioning Protection in the Brain. British Journal of Pharmacology, 140, 229-230. https://doi.org/10.1038/sj.bjp.0705441

[10] Liu, Y., Chen, L., Xu, X., Vicaut, E. and Sercombe, R. (2009) Both Ischemic Preconditioning and Ghrelin Administration Protect Hippocampus from Ischemia/Reperfusion and Upre- 
gulate Uncoupling Protein-2. BMC Physiology, 9, 17.

https://doi.org/10.1186/1472-6793-9-17

[11] Park, H.K., Seol, I.J. and Kim, K.S. (2011) Protective Effect of Hypoxic Preconditioning on Hypoxic-Ischemic Injured Newborn Rats. Journal of Korean Medical Science, 26, 14951500. https://doi.org/10.3346/jkms.2011.26.11.1495

[12] Samoulov, M.O., Rybnikova, E.A. and Churilova, A.V. (2012) Signal Molecular and Hormonal Mechanisms of Formation of the Hypoxic Preconditioning Protective Effects. Patologicheskaia Fiziologiia i EksperimentaP naia Terapiia, 56, 3-10. (In Russian)

[13] Speer, R. and Ratan, R.R. (2016) Hypoxic Adaptation in the Nervous System: Promise for Novel Therapeutics for Acute and Chronic Neurodegeneration. Advances in Experimental Medicine and Biology, 903, 221-243. https://doi.org/10.1007/978-1-4899-7678-9_16

[14] Choukèr, A., Ohta, A., Martignoni, A., Lukashev, D., Zacharia, L.C., Jackson, E.K., Schnermann, J., Ward, J.M., Kaufmann, I., Klaunberg, B., Sitkovsky, M.V. and Thiel, M. (2012) In Vivo Hypoxic Preconditioning Protects from Warm Liver Ischemia-Reperfusion Injury through the Adenosine A2B Receptor. Transplantation, 94, 894-902. https://doi.org/10.1097/TP.0b013e31826a9a46

[15] Lai, I.R., Chang, K.J., Chen, C.F. and Tsai, H.W. (2006) Transient Limb Ischemia Induces Remote Preconditioning in Liver Among Rats: The Protective Role of Heme Oxygenase-1. Transplantation, 81, 1311-1317. https://doi.org/10.1097/01.tp.0000203555.14546.63

[16] Zhuonan, Z., Sen, G., Zhipeng, J., Maoyou, Z., Linglan, Y., Gangping, W., Cheng, J., Zhongliang, M., Tian, J., Peijian, Z. and Kesen X. (2015) Hypoxia Preconditioning Induced HIF-1 $\alpha$ Promotes Glucose Metabolism and Protects Mitochondria in Liver I/R Injury. Clinics and Research in Hepatology and Gastroenterology, 39, 610-619. https://doi.org/10.1016/j.clinre.2014.12.012

[17] Bernhardt, W.M., Câmpean, V., Kany, S., Jürgensen, J.S., Weidemann, A., Warnecke, C., Arend, M., Klaus, S., Günzler, V., Amann, K., Willam, C., Wiesener, M.S. and Eckardt, K.U. (2006) Preconditional Activation of Hypoxia-Inducible Factors Ameliorates Ischemic Acute Renal Failure. Journal of the American Society of Nephrology, 17, 1970-1978. https://doi.org/10.1681/ASN.2005121302

[18] Overath, J.M., Gauer, S., Obermüller, N., Schubert, R., Schäfer, R., Geiger, H. and Baer, P.C. (2016) Short-Term Preconditioning Enhances the Therapeutic Potential of Adipose-Derived Stromal/Stem Cell-Conditioned Medium in Cisplatin-Induced Acute Kidney Injury. Experimental Cell Research, 342, 175-183. https://doi.org/10.1016/j.yexcr.2016.03.002

[19] Hawaleshka, A. and Jacobsohn, E. (1998) Ischaemic Preconditioning: Mechanisms and Potential Clinical Applications. Canadian Journal of Anesthesia, 45, 670-682. https://doi.org/10.1007/BF03012100

[20] Das, M. and Das, D.K. (2008) Molecular Mechanism of Preconditioning. IUBMB Life, 60, 199-203. https://doi.org/10.1002/iub.31

[21] Sazontova, T.G., Bolotova, A.V., Bedareva, I.V., Kostina, N.V., Yurasov, A.R. and Arkhipenko, Y.V. (2011) Hypoxia-Inducible Factor (HIF-1a), HSPs, Antioxidant Enzymes and Membrane Resistance to ROS in Endurance Exercise Performance after Adaptive Hypoxic Preconditioning. In: Wang, P., Kuo, C.-H., Takeda, N. and Singal, P.K., Eds., Adaptation Biology and Medicine, Narosa Publishing House, New Delhi, 161-179.

[22] Lukyanova, L.D., Germanova, E.L., Tsibina, T.A., Kopaladze, R.A. and Dudchenko, A.M. (2008) Efficiency and Mechanism for Different Regimens of Hypoxic Training. The Possibility of Optimization of Hypoxic Therapy. Patogenez, 6, 32-36. (In Russian)

[23] Kirova, I.I. (2012) Effect of Hypoxia on Dynamics of HIF-1Alpha Level in the Cerebral 
Cortex and Development of Adaptation in Rats with Different Resistance to Hypoxia. Patologicheskaia Fiziologiia i Eksperimental naia Terapiia, 56, 51-55. (In Russian)

[24] Purshottam, T. and Ghosh, N.C. (1972) Effect of Acetazolamide (Diamox) at Different Dose Levels on Survival Time of Rats under Acute Hypoxia and on $\mathrm{Na}^{+}-\mathrm{K}^{+}$-ATP-ase Activity of Rat Tissue Microsomes. Aerospace Medicine, 43, 610-613.

[25] Dudchenko, A.M. (1976) Comparison of Mitochondrial Dehydrogenase of Cerebral Cortex in Rats, Having Different Sensitivity to Hypoxia. In: Severin, S.E., Ed., Mitochondria: Transport of Electrons and Energy Conversion, Nauka, Moscow, 177-182. (In Russian)

[26] Berezovski, V.A., Boiko, K.A., Klimenko, K.S., Levchenko, M.N., Nazarenko, A.I. and Shumitskaya, N.M. (1978) Hypoxia and Individual Features of Reactivity. Naukova Dumka, Kiev. (In Russian)

[27] Luk'ianova, L.D. (1997) Bioenergetic Hypoxia: Definition, Mechanisms, and Methods of Correction. Bulletin of Experimental Biology and Medicine, 124, 835-843. https://doi.org/10.1007/BF02446979

[28] Sanotskaya, N.V., Matsievskii, D.D. and Lebedeva, M.A. (2004) Changes in Hemodynamics and Respiration in Rats with Different Resistance to Acute Hypoxia. Bulletin of Experimental Biology and Medicine, 138, 18-22. https://doi.org/10.1007/BF02694463

[29] Zakharova, E.I., Dudchenko, A.M. and Germanova, E.L. (2011) Effects of Preconditioning on the Resistance to Acute Hypobaric Hypoxia and Their Correction with Selective Antagonists of Nicotinic Receptors. Bulletin of Experimental Biology and Medicine, 151, 179182. https://doi.org/10.1007/s10517-011-1283-2

[30] Zakharova, E.I., Germanova, E.L., Kopaladze, R.A. and Dudchenko, A.M. (2013) Central Cholinergic Systems in the Mechanisms of Hypoxic Preconditioning: Diverse Pathways of Synaptic Reorganization in Vivo. Neurochemical Journal, 7, 45-55. https://doi.org/10.1134/S1819712413010108

[31] Kobzar, A.I. (2006) Applied Mathematical Statistics. For Engineers and Scientists. Fizmatlit, Moscow. (In Russian)

[32] Sanotskaya, N.V., Matsievskii, D.D. and Lebedeva, M.A. (2008) Effect of Picrotoxin on Organism's Resistance to Acute Severe Hypoxia. Bulletin of Experimental Biology and Medicine, 145, 177-180. https://doi.org/10.1007/s10517-008-0043-4

[33] Podolski, I.Y. (1998) Possibility of "Superfast" Consolidation of Long-Term Memory. Membrane \& Cell Biology, 11, 743-752.

[34] Zager, R.A. (2013) "Biologic Memory" in Response to Acute Kidney Injury: Cytoresistance, Toll-Like Receptor Hyper-Responsiveness and the Onset of Progressive Renal Disease. Nephrology Dialysis Transplantation, 28, 1985-1993. https://doi.org/10.1093/ndt/gft101

[35] Chizhov, A.Y. and Bludov, A.A. (2004) Mechanisms and Foundations of Resonant Hypoxitherapy. In: Lukyanova, L.D. and Ushakov, I.B., Eds., Problems of Hypoxia: Molecular, Physiological, and Medical Aspects, Istoki, Voronezh, 519-568. (In Russian)

[36] Potievskaia, V.I. and Potievsky, B.G. (2008) Peculiarities of Oxygen Metabolism Kinetics in the Period of Adaptation to Hypoxia in Patients with Internal Diseases. Patogenez, 6, 37-39. (In Russian)

[37] Tabata, M., Kurosawa, H., Kikuchi, Y., Hida, W., Ogawa, H., Okabe, S., Tun, Y., Hattori, T. and Shirato, K. (2001) Role of GABA within the Nucleus Tractus Solitarii in the Hypoxic Ventilatory Decline of Awake Rats. American Journal of Physiology, 281, R1411-R1419.

[38] Sanotskaya, N.V., Matsievskii, D.D. and Lebedeva, M.A. (2012) Acute Hypoxia Influence on Pulmonary and Systemic Blood Circulation. Patogenez, 10, 56-59. (In Russian)

[39] Waseem, M., Khan, I., Iqbal, H., Eijaz, S., Usman, S., Ahmed, N., Alam, G. and Salim, A. 
(2016) Hypoxic Preconditioning Improves the Therapeutic Potential of Aging Bone Marrow Mesenchymal Stem Cells in Streptozotocin-Induced Type-1 Diabetic Mice. Cell Reprogram, 18, 344-355. https://doi.org/10.1089/cell.2016.0002

[40] Pshennikova, M.G., Bondarenko, N.A., Shimkovich, M.V., Bondarenko, O.N. and Malyshev, I.Iu. (1999) Differences in the Behavior and Resistance to Stomach Ulcer during Stress in August and Wistar Rats Adapted and Not Adapted to Hypoxia. Bulletin of Experimental Biology and Medicine, 128, 1213-1215. https://doi.org/10.1007/BF02434820

[41] Pshennikova, M.G., Popkova, E.V. and Shimkovich, M.V. (2002) Adaptation to Stress Improves Resistance to Gastric Damage during Acute Stress in Wistar Rats and Decreases Resistance in August Rats: Role of Serotonin. Bulletin of Experimental Biology and Medicine, 134, 329-332. https://doi.org/10.1023/A:1021987626693

[42] Pshennikova, M.G. (2011) Role of Genetic Peculiarities in Resistance of the Body to Detrimental Impacts and Protective Effects of Adaptation. Patologicheskaia Fiziologiia i Eksperimental naia Terapiia, 55, 7-16. (In Russian)

\section{Submit or recommend next manuscript to SCIRP and we will provide best service for you:}

Accepting pre-submission inquiries through Email, Facebook, LinkedIn, Twitter, etc. A wide selection of journals (inclusive of 9 subjects, more than 200 journals)

Providing 24-hour high-quality service

User-friendly online submission system

Fair and swift peer-review system

Efficient typesetting and proofreading procedure

Display of the result of downloads and visits, as well as the number of cited articles

Maximum dissemination of your research work

Submit your manuscript at: http://papersubmission.scirp.org/

Or contact jbise@scirp.org 